\title{
IDEALIZED SIMULATION OF OROGRAPHIC RAINFALL WITH A MESOSCALE ATMOSPHERIC MODEL
}

\author{
Assela PATHIRANA ${ }^{1}$ and Tadashi YAMADA ${ }^{2}$ \\ ${ }^{1}$ Member of JSCE, D. Eng., United Nations University, \\ 53-70, Jingumae 5-chome, Shibuya-ku, Tokyo 150-8925, JAPAN. E-mail: asselapathirana@yahoo.co.jp \\ ${ }^{2}$ Member of JSCE, D. Eng., JSCE Corp., Faculty of Science and Engineering, Chuo University, \\ 1-13-27, Kasuga, Bunkyo-ku, Tokyo 112-8551 JAPAN.
}

\begin{abstract}
The impact of different atmospheric and topographic conditions on the rainfall distribution around a single, infinitely long ridge is investigated. The main objective of the study was to understand the conditions that are responsible for commonly observed rainfall patterns like high rainfall yields on the side of the ridge facing the wind and rain-shadows on the lee side. A modified version of MM5, a non-hydrostatic model that is widely used for limited area atmospheric simulations for research and operational purposes, was used for this study. The effects of different mountain ridge dimensions, large-scale wind conditions and large-scale moisture profiles on the amount and distribution of orographic precipitation, were clarified. Ridge height has a positive correlation with the amount of rainfall generated while the ridge width did not show such a clear relationship. Slowing of wind speed resulted in the spreading of rainfall outwards from the mountain peak. Reduction of moisture caused a reduced rainfall yield. Most of the simulations produced highest rainfall amounts on the windward slopes. However, changing the topography, wind speed or moisture, a rain shadow condition could not be attained. The introduction of a reversal of the winds in the upper atmosphere as observed in Asian summer monsoon and many other large-scale atmospheric flows on the globe, created a rain shadow by confining the rainfall completely to the upstream of the ridge top.
\end{abstract}

Key Words: Mesoscale Atmospheric Model, Orographic Precipitation, Idealized Simulations

\section{INTRODUCTION}

Interaction of large topographical features with a wind field has dramatic effect on the generation of rainfall. It is observed and widely accepted that a mountainous terrain generally receives more rainfall than than lowland in the same geographic region and as a result there is a positive correlation between elevation and average rainfall yield. Rainfall in the worlds most rainy climates are determined by the different atmospheric mechanisms that are critically dependent on the presence of mountainous areas, making the knowledge on orographic rainfall a much needed ingredient of strategic planning on sustainable use of water resources or on water related disaster mitigation. Water availability of worlds major rivers depend on the rainfall occurring on mountainous watersheds.

The physical relationships that govern the atmospheric dynamics and the other phenomena related to rainfall generation, like phase changes of water substance, have long been formulated with sufficient clarity. When a large number of different factors that govern the destiny of water in the atmosphere interact, the resulting conditions are generally complex that the only feasible approach of resolving the water budget in the atmosphere is the use of numerical solution methods. Modern numerical models with complete sets of dynamical equations can forecast atmospheric conditions in the short-term, given suitable initial/boundary conditions and are widely used for operational and research purposes. However, the real atmospheric conditions are generally complicated due to the simultaneous action of a number of influences like constant and often rapid change of winds, pressure patterns, moisture, etc. Therefore, numerical simulations under controlled conditions of an idealized environment can contribute to the understanding of the influence of each of the factors that influence the rainfall patterns.

The dynamical behavior of the airflow over a mountain is a problem that has been subjected to extensive theoretical investigation (see Smith ${ }^{15}$ ) for a review) and more recently to a number of numerical studies involving both real and idealized settings ${ }^{8) 1)}$ ). Pathirana et al. ${ }^{11)}$ used version 2 of the MM5 model to 


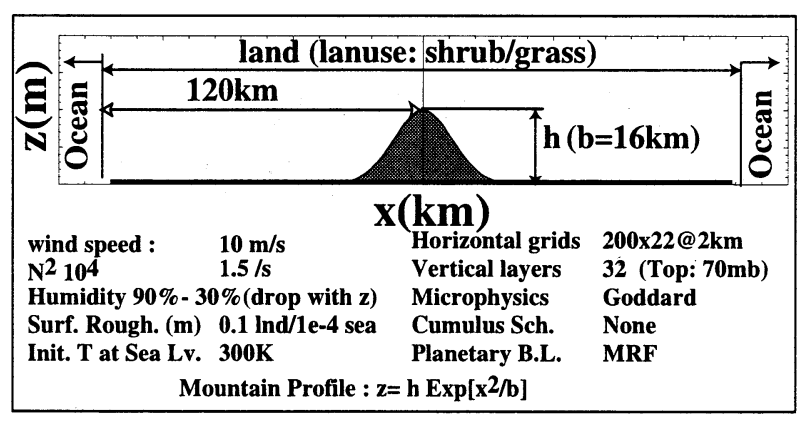

Fig. 1 Model configuration.

Table 1. Temperature (T) and moisture profiles (M.P.). Relative humidity given in percentages.

\begin{tabular}{|lrrrrrrrr|}
\hline P (hPa) & 1000 & 950 & 850 & 700 & 500 & 400 & 300 & 100 \\
T (K) & 300 & 298 & 293 & 284 & 269 & 259 & 246 & 200 \\
M.P. I & 95 & 95 & 95 & 95 & 80 & 75 & 50 & 30 \\
M.P. II & 95 & 95 & 85 & 80 & 75 & 40 & 30 & 30 \\
M.P. III & 90 & 85 & 70 & 60 & 50 & 40 & 30 & 30 \\
\hline
\end{tabular}

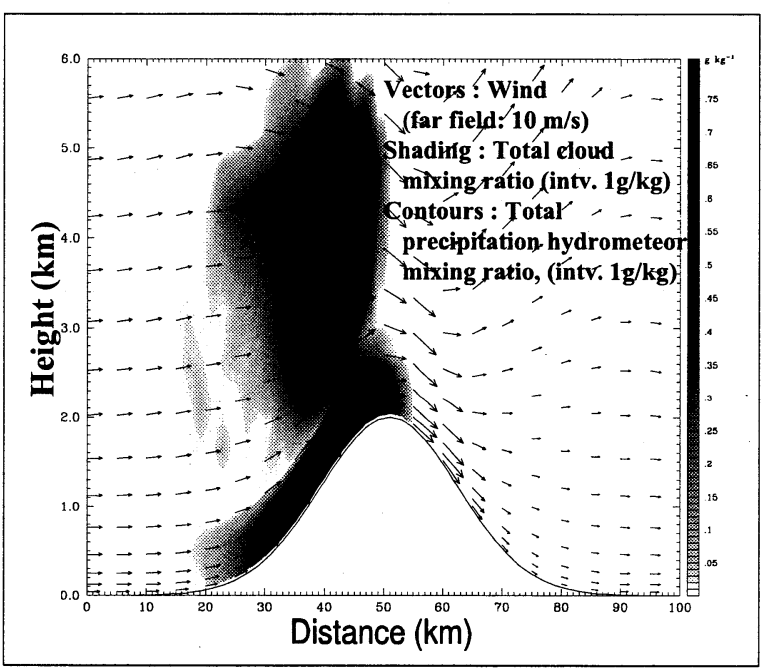

Fig. 2 Clouds after 10min of model start.

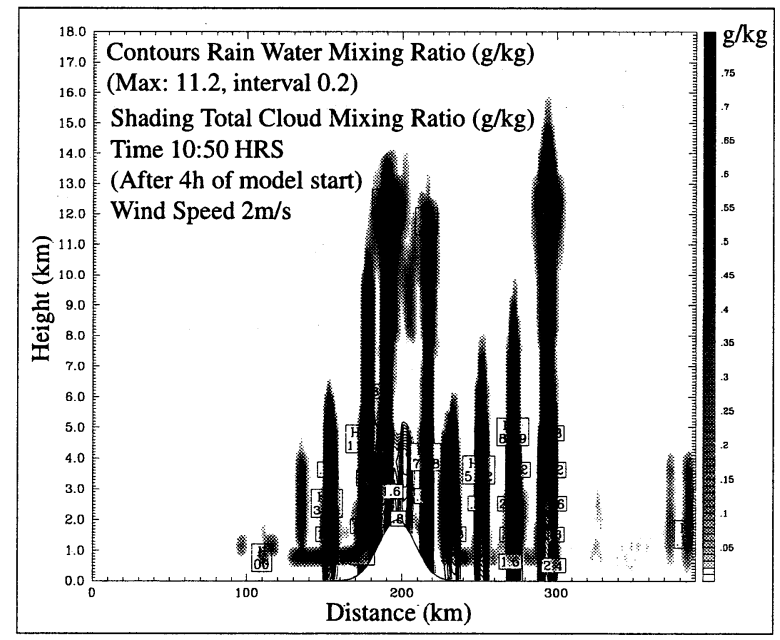

Fig. 3 Clouds and rainfall generated by convection triggered by mountain flow.

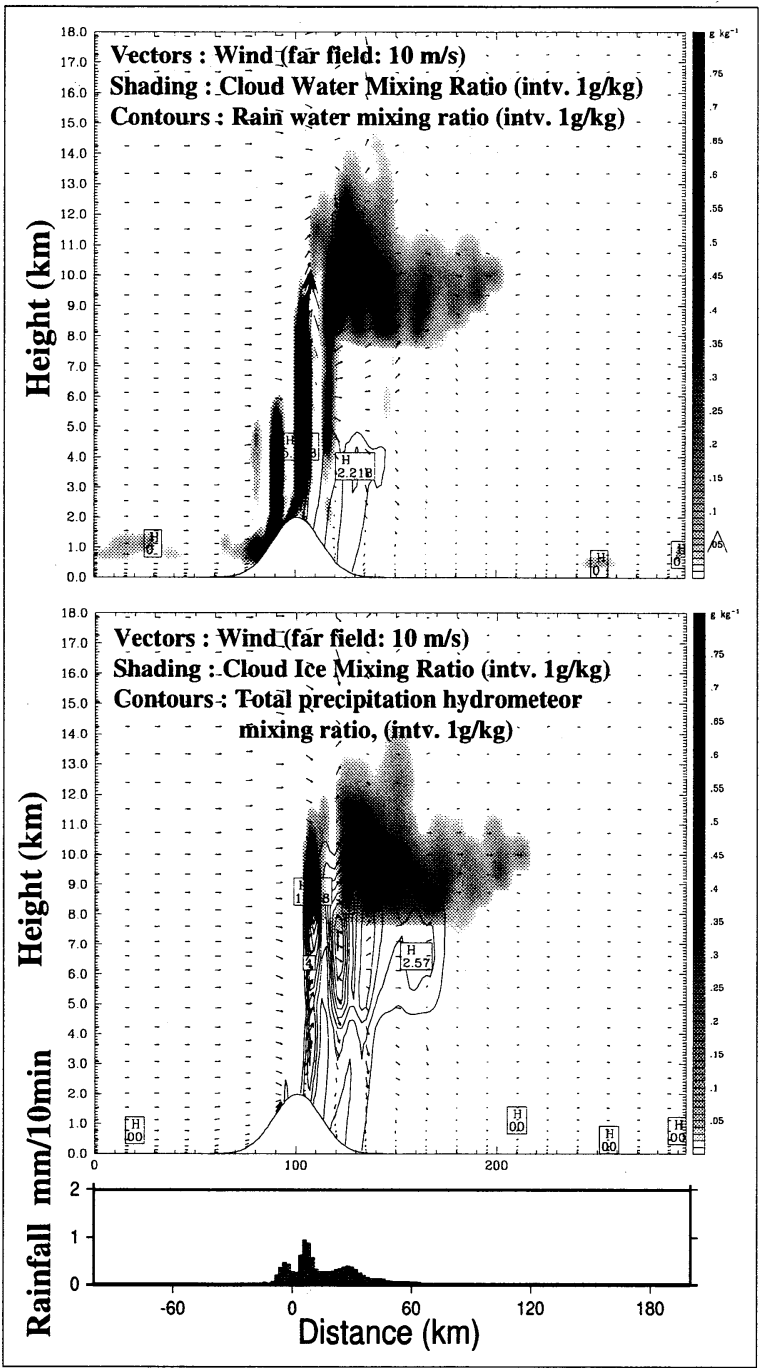

Fig. 4 Top and Middle: Development of clouds (200min after start). Bottom: Corresponding rainfall.

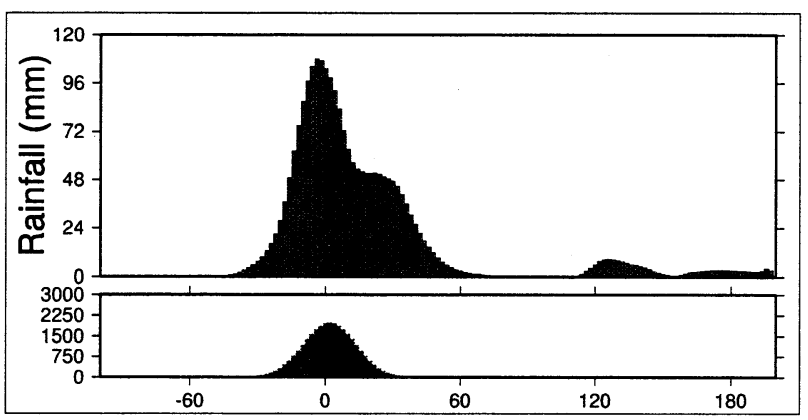

Fig. 5 Cumulative rainfall in $24 \mathrm{~h}$ for the control run. The topography shown below. 
investigate the formation of lee-waves and rotors associated with mountain flow. Those idealized studies have focused on the dynamics of dry air, without incorporating the phase change of water substance and the rainfall generation. On the other hand, there have been studies on rainfall generation associated with topography: For example, Hibino et al. ${ }^{5)}$ studied the effects of mountain height and slope-angle on rainfall orographic rainfall generation using a combination of a numerical model based on potential-flow and the bulk parameterization by Rutledge and Hobbs ${ }^{13}$. They concluded that while the mountain height has significant effect on precipitation amount, the slope does not. Oishi et al. ${ }^{9)}$ also carried out numerical simulations and showed that down draught forced topography can cause heavy rainfall.

The objective of the present research was to understand the effect of different topographic and atmospheric parameters on the rainfall due to the interaction of large-scale wind fields with a long uniform ridge profile. An effort was made to identify conditions under which the rainfall is mainly limited to the wind side of the ridge, causing rain-shadows in the leeward slopes. The following sections present the methodology, details about selected experiments, results and conclusions.

\section{MODEL DESCRIPTION}

The fifth generatoin Pennsylvania State University/National Center for Atmospheric Research mesoscale model, MM5 ${ }^{24)}$ ) solves a fully compressible, non-hydrostatic set of governing equations (for prognostic variables of velocity, pressure perturbation and temperature) on a terrain following $(\sigma-z)$ coordinate system. The model requires the specification of the initial conditions all over the modeling domain and the lateral boundary conditions during the whole time period of model integration. Boundaries need to have specified horizontal winds, temperature, pressure and moisture conditions and optionally microphysical fields. In an operational scenario, the lateral boundary data are usually obtained from a global scale model results or analyses at some intermediate spatial scale, which ultimately depend on a global model. In historical studies lateral boundary conditions can be enhanced using observational data. Performing idealized simulations is not a standard usage of the modeling system and therefore a number of additional modifications of the prepossessing programs are needed before the model can be used for the purpose similar to the one of the present research. However, there are a number of distinct advantages in using MM5 as the basis for an idealized study. The model has been in operational and research use worldwide for more than a decade, resulting in a well-tested numerical system. The model source is freely available for use. Further, due to the model's ability to perform simulations based on real observational data and large-scale model outputs with relative ease, it is feasible to extend the ideal simulations to those using real data in future work, without switching models.

The available pre-processor programs of MM5 model sets up the model grid including surface topography using standard geographical datasets like GTOPO-30 of United States Gegraphical Survey. Further, they produce initial and lateral forcings using standard three dimensional pressure level datasets (first-guess fields) together with surface observations and soundings. In order to perform idealized simulations both these steps has to be altered to ingest idealized conditions. In the present research the former is achieved by producing fake GTOPO-30 like data cells with the desired idealized topography, for the standard preprocessor program to access. With this approach the need to reprogram the model domain setup preprocessors is eliminated. To provide idealized forcing data, an alternative preprosessor program was created to provide the 3-d fields using the values for the horizontal wind velocities ( $w$ usually taken as zero), temperature and humidity (as relative humidity) at different pressure levels. Geopotential height is computed using the following relation derived from hydrostatic equation $(-d p=g \rho d z$, where $\rho$ is density)

$$
\left(Z_{2}-Z_{1}\right)=\frac{R_{d}}{g_{0}} \frac{\log \left(P_{1} / P_{2}\right)\left(T_{v 2}-T_{v 1}\right)}{\log \left(T_{v 2} / T_{v 1}\right)}
$$

for lower layers where $T_{v} \approx T_{v 0}-\Gamma^{\prime} Z$ and

$$
\begin{array}{r}
\left(Z_{2}-Z_{1}\right)=\frac{R_{d}}{g_{0}} T_{v} \log \left(P_{1} / P_{2}\right) \\
\text { for isothermal layers }
\end{array}
$$

where $R_{d}, g_{0}, \Gamma$ are dry gas constant, globally averaged gravitational acceleration and lapse rate of temperature with height, respectively. $T_{v}$ is virtual temperature defined by

$$
T v=T\left[1+0.61\left(w_{s} \frac{R H}{100}\right)\right]
$$

where $w_{s}$ is the saturation mixing ratio of water and $R H$, relative humidity. A small adjustment based on horizontal velocity and latitudinal position, is applied to geopotential height to make the fields geostrophically balanced (details omitted).

\section{SIMULATIONS}

Fig. 1 and Table 1 shows the important model parameters. Due to the possibility of cloud formation at relatively high altitudes the model top was selected at 

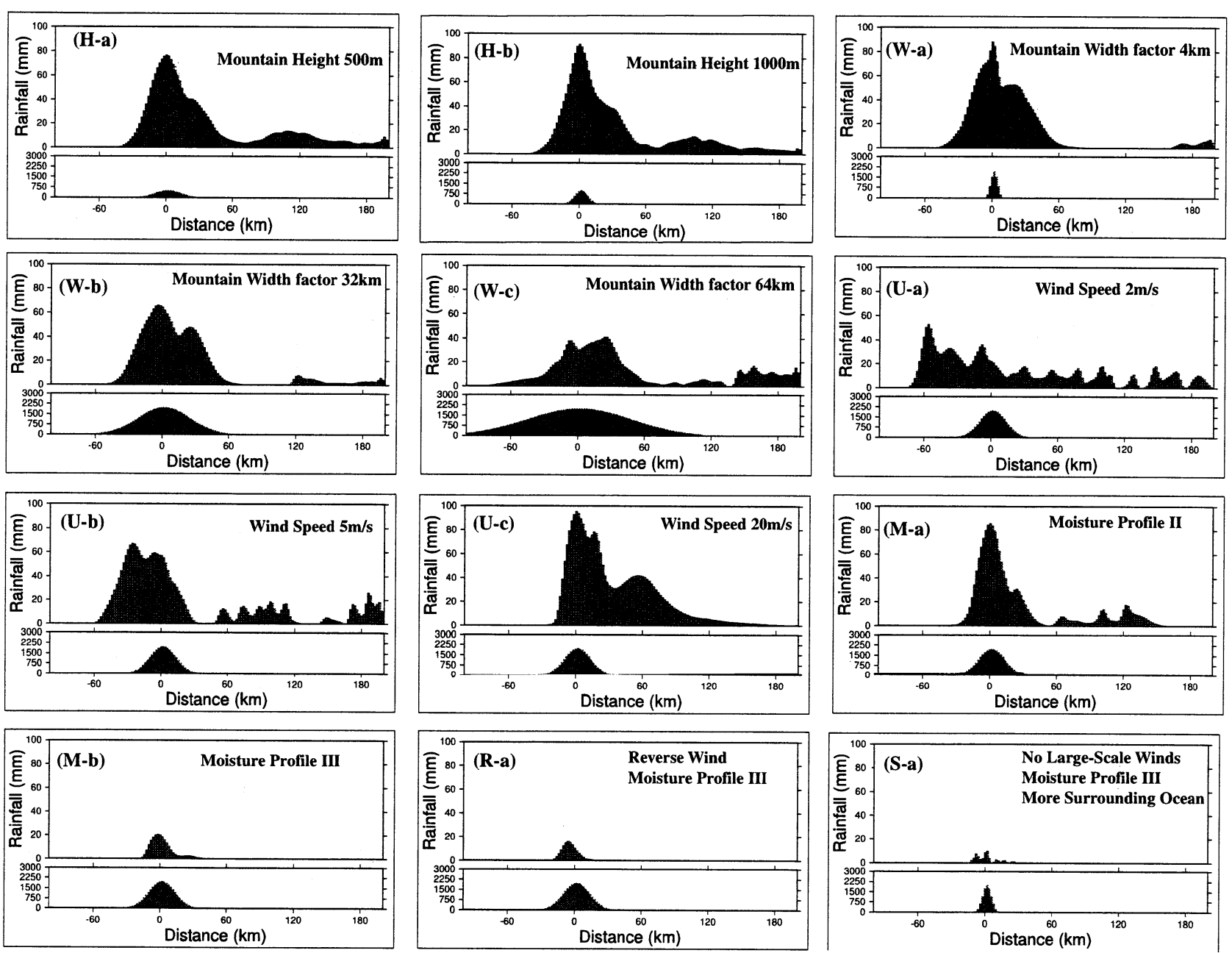

Fig. 6 Distribution of rainfall accumulated over $24 \mathrm{~h}$ period. $(\mathrm{H}-\mathrm{a}, \mathrm{b})$ : Different ridge heights. (W-a,b,c): ridge width factors $(b)$. (U-a,b,c): wind speeds. (M-a,b): Moisture profiles. (R-a): Presence of reverse flow in uppper atmosphere. (S-a) Case with no large-scale winds. (Corresponding ridge profile is shown below each plot.)

$70 \mathrm{mb}$ (about $16 \mathrm{~km}$ ). Since the grid size is relatively small $(2 \mathrm{~km})$, it is desirable to neglect the cumulus parameterization $^{12)}$, leaving the explicit resolving of moisture as the only rainfall generation scheme. Goddard microphysics scheme ${ }^{16)}$, which has equations for vapor, cloud water, rain water, snow and graupel, was used for explicit resolving of moisture. The planetary boundary layer was represented by the Hong-Pan PBL scheme as implemented in NCEP MRF model $\left.{ }^{6}\right)$ together with a single variable temperature soil slab above fixed-temperature substrate.

The atmospheric condition was set to reflect the typical conditions in the tropics. The temperature profile was selected such that the Brunt-väisälä frequency $\left(N^{2}=g / T\left(\partial T / \partial z+g / C_{p}\right)\right.$ for dry air, see Durran and $\mathrm{Klemp}^{3)}$ for definitions for moist air), is roughly a constant value of $1.510^{-4}$. The effects of clouds and diurnal cycle in atmospheric radiation were considered. Sea level temperature was set at $300 \mathrm{~K}$. Computation was started at $0600 \mathrm{~h}$ (local time, in the morning) and the effect of solar heating was considered.
The model was integrated at $6 \mathrm{~s}$ time-steps and each run was continued for a full $24 \mathrm{~h}$ cycle, producing output at every $10 \mathrm{~min}$.

In order to understand the effects of various topographic and atmospheric factors, a number of simulations were done by changing the model parameters. The first model run (hereafter referred to as the control run) was conducted using a mountain with $H=2000 \mathrm{~m}$ and $b=16 \mathrm{~m}$. The wind condition was set at $10 \mathrm{~m} / \mathrm{s}$, constant with elevation. The moisture profile was such that the lower layers are nearly-saturated $(R H>90 \%)$ and then dropping to a value less than $30 \%$ above $450 \mathrm{hPa}$ level. Table 1 lists the temperature and moisture profiles (M.P. I in the table) used. In the following sections the effects of changing Mountain height, Mountain width, Wind speed, Moisture profile and Wind profile, are discussed. In each of these experiments only the relevant parameter was changed while keeping others equal to those of control run. 


\section{RESULTS}

Several minutes after the model initialization, the clouds first start to appear above the wind-side slope of the mountain. These clouds are of very low altitude (only several hundred meters above mountain surface). Fig. 2 shows the cloud structure after $10 \mathrm{~min}$ of model start. The low-level cloud's base is at the level of the surface, so that this type of clouds may appear as fog to an observer on the mountain top. This type of clouds, due to their appearance as a wall to an observer on the lee-side, are known as a Fohn-wall. These are generally nonprecipitating clouds due to their lower elevation. However, lowelevation clouds can sometimes precipitate by working together with clouds aloft that are capable of providing large precipitation particles (Seeder-Feeder mechanism ${ }^{7)}$ ). Though the simulation have generated a high-elevation cloud system aloft, there is no precipitation formed at this time.

During the next several $10 \mathrm{~min}$ periods, the clouds develop rapidly in height aided by convective breakup due to the combined effect of topography and landheating. These dense clouds with sharp outlines that develop vertically in the form of rising mounds $(\mathrm{Cu}-$ mulus) later develop in to precipitating clouds referred to as Cumulonimbus under favorable conditions. Cumulonimbus is often characterized by the development of an anvil - the top part of the cloud that develops rapidly in the direction of wind (Fig. 4). It was observed that when the topography is higher, this growth takes place faster (within $2 \mathrm{~h}$ in $2000 \mathrm{~m}$ whereas $500 \mathrm{~m}$ takes about $4 \mathrm{~h}$ ). As indicated by fig. 4middle, the anvil is often made of ice crystals. A significant amount of rainfall starts to appear only after this cloud escalation and anvil development. The rain starts near the peak and then spreads towards the leeside slope as the clouds spread that way. The precipitation starts often as snow or ice, but later transformed into liquid rain as it descends to warmer lower levels of the atmosphere. However, some of the precipitation never reaches the surface (e.g. about $150 \mathrm{~km}$ downstream of the ridge-peak) and gets re-evaporated during the decent through the atmosphere. This process in known as virga ${ }^{10)}$. In the control run, the convective development occurs mostly on the slopes of the mountains. However, at lower speeds, the convective breakup occurs in the surrounding slopes as well (Fig.3).

After solving the model for a $24 \mathrm{~h}$ period, the rainfall amount accumulated over that period was plotted. Fig. 5 is the distribution of this rainfall along a longitudinal cross section, for the control run. Fig. 6 shows the same for a number of cases with different model parameters.

There are some features of accumulated rainfall that are common to all the simulations performed: The general tendency is that the plains that are further away from the mountain gets relatively less rainfall compared with the slopes. However, non of the cases had the rainfall maxima at the peak of the ridge, but at a point some distance upstream of the peak. This is in agreement with rainfall patterns of some monsoon climates $^{17)}$. All the cases using moisture profiles I and II (Table 1) show a significant rainfall amount falling on lee-side plains, in addition to the rain on windward slope and ridge-top.

The mountain height has a positive correlation with the rainfall: Rainfall peak over the mountain as well as the total rainfall amount (results not shown) increased with ridge height. However, the rainfall amount on the downstream was not significantly affected. The increase of the width of the mountain leads to a decrease of ridge-top rainfall and an increase of rain on lee-side. This is contradictory to some of the accepted patterns of orographic rainfall. For example Smith ${ }^{14)}$ has stated that wider mountains cause lee-side rain shadows.

The results show a remarkable effect of wind speed on rainfall distribution: For low velocities the rainfall peak can occur more than $50 \mathrm{~km}$ upwind from the crest. The overall rainfall pattern shows a distinct waviness, suggesting the possibility of mountain wave action. However, while all the cases generated gravity waves due to the ridge, they are of untrapped nature progressing nearly vertical above the ridge. The examination of the cloud structure (fig. 3) indicated that the rainfall at lower velocities are driven mainly by deep convection triggered due to the flow modification by the mountain as discussed by Houze $^{7)}$. Cases with higher large-scale wind velocities had most of the convective activities around the peak. However, the rainfall was not restricted only to the wind side of the mountain slope. The reason for the second (often smaller) rainfall peak at the lee-side may be the convection triggered by the interaction of the moist sea-breeze, warmed up over the land with drier and (relatively) cooler downslope wind.

The effect of reducing moisture causes reduction of peak over the mountain top. However, when the moisture profile is reduced to that of M.P. III (Table 1), the air becomes critically depleted of vapor by the upslope-condensation and other upwind-slope procesees, so that the convective rainfall on the leeside becomes very much restricted (fig. 6M-b).

The actual wind profile of the summer monsoon, for example in Indian Ocean, is very much different from the constant wind fields used in the preceding analyses. Due to the action of the tropical easterly jet in the upper troposphere, the wind velocities gradually drop from a maximum near surface to a negative flow above a $6-7 \mathrm{~km}$ height. Fig. $6 \mathrm{R}$-a shows the re- 
sults of a simulation with wind reversal above $6 \mathrm{~km}$ height. The rainfall peak has moved further upwind compared with case $\mathrm{M}-\mathrm{h}$ and there is almost no lee side rainfall. This pattern is quite in agreement with what is happening in some monsoon climates, e.g. Sri Lanka: The summer monsoon enters the island from west and passes through the central mountains, causing heavy rainfall on the western slopes, while the eastern slopes and plains remain dry during the season.

Finally, fig. 6S-a shows the results of a simulation with no large-scale wind field. (It should be noted that this particular simulation was done in a nested grid setup with about $400 \mathrm{~km}$ of ocean on either side of the land, in order to have sufficient water space for sea-breeze to develop in the numerical domain.) Due to the differential heating of Ocean and land, the convergence of wind occurs over the mountain, causing small amounts of rainfall on and around the mountain.

\section{CONCLUSIONS}

A number of idealized simulations of the atmosphere surrounding a single mountain ridge was done, with changing different model parameters. Many features that are observed in orographic systems like Fohn wall, development of cumulus and cumulonimbus clouds, virga process and anvil formation were reproduced at different stages of simulations. Most of the simulations agree with the common observations of increase of accumulated rainfall with altitude, relatively larger rainfall amounts on upwind slopes compared with downwind slopes and the occurrence of rainfall maxima on some distance upwind of the mountain peak. However, the exact distribution of rainfall is remarkably different among simulations with differing parameters. Effects of upslopecondensation, convection and convergence of seabreeze above the mountain ridge dominated in different scenarios. However, the net accumulated rainfall of many simulations were contributed by more than one of these parameters.

None of the simulations with different ridge elevation, width, wind speed or moisture caused complete dryness on the lee-side. However, by the introduction of reversal of the wind field at the upper troposphere as it happens with many large-scale circulations in the globe, conditions of rain shadow was attained. This result suggests that the prevailant rainfall patterns around mountains in the path of largescale floor, namely high rainfall on upstream slopes and virtually no rain on the downstream of the peak, are critically defendant on the occurrence of wind reversal in the upper atmosphere.
Acknowledgments: This work has been funded by a grant from the Japan Society for Promotion of Science.

\section{REFERENCES}

1) J. D. Doyle and D. R. Durran. The dynamics of mountain-wave-induced rotors. Journal of Atmospheric Science, 59:186-201, 2001.

2) J. Dudhia. A non-hydrostatic version of the Penn State-NCAR mesoscale model: validation tests and simulation of an atlantic cyclone and cold front. Monthly Weather Review, 121:1493-1513, 1993.

3) D. R. Durran and J. B. Klemp. On the effects of moisture on the brunt-väisälä frequency. Journal of Atmospheric Science, 39:2152-2158, 1982.

4) G. Grell, J. Dudhia, and D. Stauffer. A description of the fifth-generation penn state/ncar mesoscale model (mm5). Technical Report NCAR/TN-398+STR, National Center for Atmospheric Research, 1996.

5) T. Hibino, M. Nakatsugawa, and T. Yamada. Wind field in meso- $\beta$ scale caused by orographic effect. In: Proceedings of XXV Congress of IAHR, pages 135142, 1993.

6) S. Y. Hong and H. L. Pan. Nonlocal boundary layer vertical diffusion in a midium-range forecast model. Monthly Weather Review, 124:2322-2339, 1996.

7) R. A. Jr. Houze. Cloud Dynamics, chapter Orographic Clouds, pages 502-538. Academic Press, 1993.

8) L. B. Nance and D.R. Durran. A modeling study of nonstation-ary trapped mountain lee waves, part i: Mean flow variability. Journal of Atmospheric Science, 54:2275-2291, 1997.

9) S. Oishi, Y. Kitani, E. Nakakita, and S.Ikebuchi. Study on effect of updraft on precipitaion processes using two-dimensional cumulus model. Journal of Hydroscience and Hydraulic Engeineering , Vol.14,No.2,pp.81-88, 1996, 14(2):81-88, 1993.

10) World Meteorological Organization, editor. International Cloud Atlas. World Meteorological, June 1977.

11) A. Pathirana, M. Yamaguchi, and T. Yamada. Idealized simulation of airflow over a mountain ridge using a mesoscale atmospheric model. Annual Journal of Hydraulic Engineering, JSCE, 47:31-36, 2003.

12) R. Pilke. Mesoscale Meteorological Modeling. Academic Press, San Diego, California, 2 edition, 2002.

13) S.A. Rutledge and P.V. Hobbs. The mesoscale and microscale structure and organization of clouds and precipitation in mid-latitude cyclones. viii: A model for the seeder-feeder process in warm-frontal rainbands. J. Atmos. Sci, 40:1185-1509, 1983.

14) R. B. Smith. The influence of mountains of the atmosphere. Advances in Geophysics, 21:87-230, 1979.

15) R.B. Smith. Hydrostatic airflow over mountains. $A d-$ vances in Geophysics, 31:1-41, 1989.

16) W.K. Tao and J. Simpson. Goddard cumulus ensemble model. part i: Model description. Terrestrial, Atmospheric and Oceanic Sciences, 4:35-72, 1993.

17) L. Zubair. A dynamical model for orographic rainfall in sri lanka. In Proceedings of Asian Fluid Dynamics Congress, volume 8, pages 864-867, Shenzen, China, December 1999. 